\title{
EVALUATION OF CREEP-FATIGUE STRENGTH OF P122 HIGH TEMPERATURE BOILER MATERIAL
}

\author{
John Pumwa, Ph.D., CEng., MIMechE \\ Mechanical Engineering Department \\ Papua New Guinea University of Technology \\ Private Mail Bag Service \\ Lae, MP 411 \\ PAPUA NEW GUINEA \\ Phone/Fax: (675) 4734851 \\ E-mail:jpumwa@mech.unitech.ac.pg
}

\begin{abstract}
In components which operate at high temperatures, changes in conditions at the beginning and end of operation or during operation result in transient temperature gradients. If these transients are repeated, the differential thermal expansion during each transient may result in thermally induced cyclic stresses. The extent of the resulting fatigue damage depends on the nature and frequency of the transient, the thermal gradient in the component, and the material properties. Components, which are subjected to thermally induced stresses generally, operate within the creep range so that damage due to both fatigue and creep has to be taken into account. In order to select the correct materials for these hostile operating environmental conditions, it is vitally important to understand the behaviour of mechanical properties such as creep-fatigue properties of these materials. This paper reports the results of standard creep-fatigue tests conducted using P122 (HCM12A or $12 \mathrm{Cr}-1.8 \mathrm{~W}-1.5 \mathrm{Cu})$ high temperature boiler material. $\mathrm{P} 122$ is one of the latest developed materials for high temperature environments, which has the potential to be successful in such hostile operating environments. The tests were conducted at temperatures ranging from $550^{\circ} \mathrm{C}$ to $700{ }^{\circ} \mathrm{C}$ at $50^{\circ} \mathrm{C}$ intervals with strain ranges of \pm 1.5 to $\pm 3.0 \%$ at $0.5 \%$ intervals and a strain rate of $4 \mathrm{x}$ $10^{-3} \mathrm{~s}^{-1}$ with an application of 10-minute tensile hold time using a closed-loop hydraulic Instron material testing machine with a servo hydraulic controller. The results confirm that P122 is comparable to conventional high temperature steels.
\end{abstract}

